\title{
Anma, Marpla and Ngapartji Ngapartji: Insights Into how to do Research Together in 'Good Faith'
}

\author{
Lisa Hall \\ Batchelor Institute of Indigenous Tertiary Education \\ lisa.hall@batchelor.edu.au
}

Keywords: Research, Indigenous, education, time, relationship, reciprocity, good faith.

\begin{abstract}
This paper is a reflection and discussion on doing decolonising research in the intercultural space. It flows from a larger $\mathrm{PhD}$ research study on pathways for Indigenous people from remote communities into teacher education. Academic research is steeped in western colonised traditions and behaviours. Conscious of this, it was important while undertaking the work toward this thesis to pay attention to the process of working together within the research. This came out of a desire to embody rather than observe cultural and ethical guidelines about doing research involving Indigenous people and knowledge systems. Through a series of interrupting tools used throughout the work, some key insights were captured that were significant in illustrating one process for collaborative decolonizing research. Three insights in particular stood out as guides for how to do decolonising research in the intercultural space. This paper will explain and discuss these three areas and their implications for working in what Verran (2013) calls 'good faith'.

Note: While I (Lisa) acknowledge that I am the sole named author of this paper, and that carries with it an inherent hegemony, at various times in this paper I have used the collective pronouns of 'we' and 'us' to honour the collective process used in conducting this research with the teacher participants.
\end{abstract}

\section{Introduction}

This paper stems from doctoral research focused on pathways into teacher education for Indigenous people from remote communities in Central Australia. The principal, nonIndigenous, researcher worked with a group of Indigenous 'teacher participants' who are fully qualified teachers from the communities shown in Figure 1: Western Arrarnta (1), Warlpiri (2), Pintupi Luritja (3) and Pitjantjatjara (4), which are located in Central Australia (Figure 2).

Through a process of listening to, recording and analysing teacher narratives, the research explored the supports and barriers for Indigenous people from remote communities becoming qualified teachers. The purpose was to discern some of the reasons why so few young people from remote communities in Central Australia are completing teacher education. In considering how to explore this topic of common concern, it was important to acknowledge the inherent power relationship that exists in research work (Arbon, 2008; Moreton-Robinson, 2004; Smith, 1999; Wilson, 2008). In the case of this research there was a specific power imbalance, that reflects entrenched hegemonies, given that the principal researcher is non-Indigenous and all the research participants are Indigenous. This type of power imblance has wrought huge damage to Indigenous communities in the past, and it continues to impact on Indigenous 
people. So it was equally important to all involved to ensure that this particular research project happened in a way that was conscious and alert to the colonised power relationships and practices of past research in this field. We tried wherever possible to operate in ways that did not perpetuate those practices. To that end, the research drew on the guidance of both Indigenous and non-Indigenous scholars.

Figure 1: Central Australian communities of the teacher participants

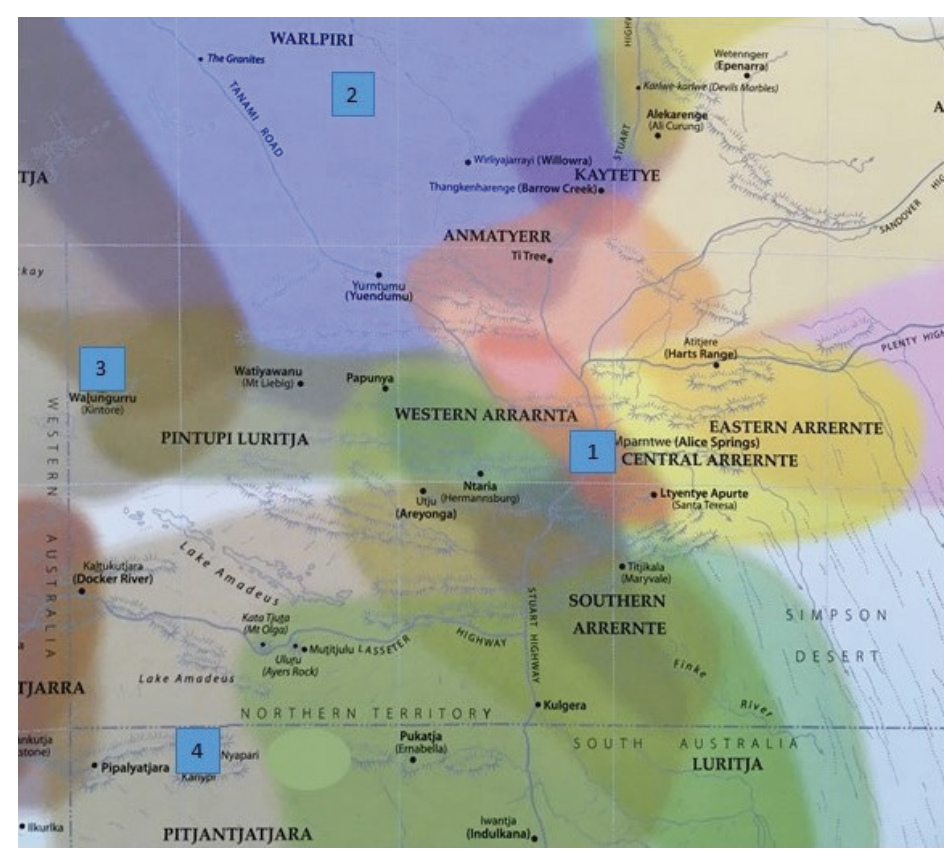

Source: Institute for Aboriginal Development (2002).

Figure 2: The region known as Central Australia

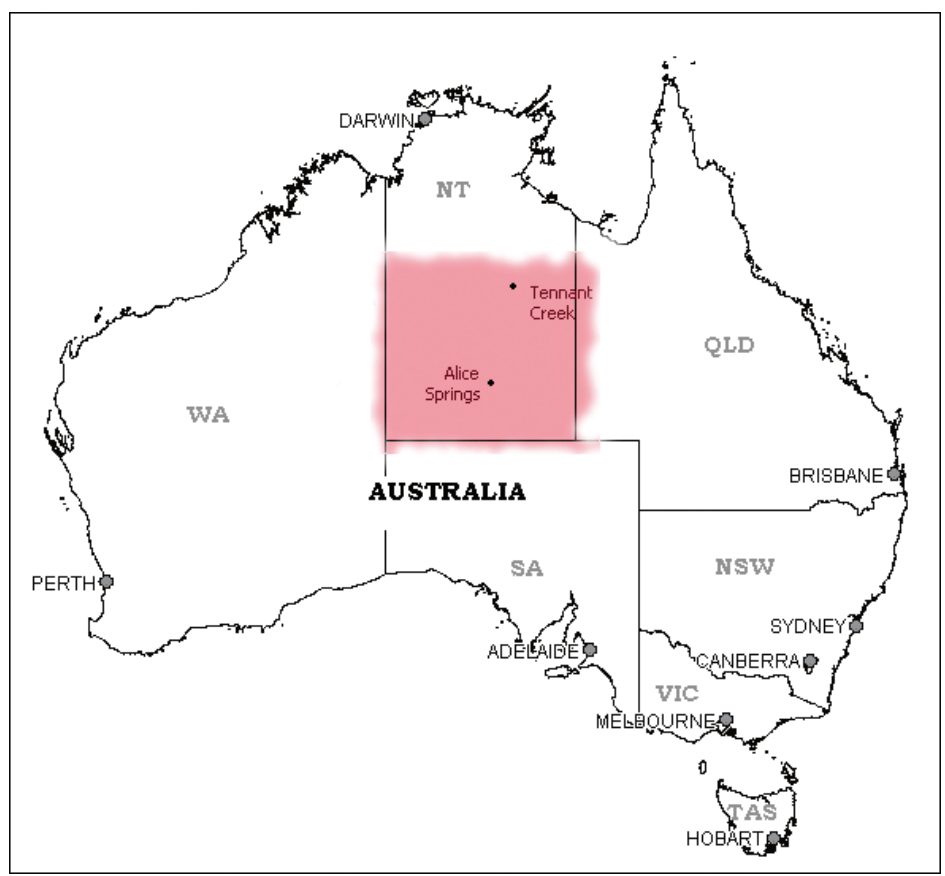

Source: Wearne (2003). 


\section{Background and Rationale}

Relationships were a central guide to how we worked together (Martin 2008). The idea for the research itself grew out of pre-existing relationships from previous work I had undertaken with these teachers. I had worked with them as their lecturer when they were studying. Through two and a half years of working together during the final stage of a teacher education degree I was privileged to hear the stories of how these mature-aged women became teachers in the first place. In some ways it felt like those stories were being entrusted to me to hold onto, to remember, to contextualise in my work with these women and their respective communities, and to differentiate from my own story and journey to become a qualified teacher. But it also felt like the women were giving me those stories to do something with them. In many ways this description by Linda Tuhiwai Smith (1999, p. 197) best describes this feeling:

I found that people entrusted me with information about themselves which was highly personal, I felt honoured by that trust, and somewhat obligated as well - in the sense of having to be very careful and very respectful about how I handled such information.

I have no proof or evidence that this is what the teachers were asking me to do with their stories, other than our collective ongoing commitment to the research, and an intuitive understanding that has not diminished over time. It was also an area I repeatedly sought guidance on from one of my PhD supervisors, Aboriginal scholar Dr Payi Linda Ford, as the process unfolded. So the idea for this research was born out of relationships. The PhD process was used as a vehicle to explore the wider learning that might be gleaned from these teacher stories.

In spite of, and perhaps even because of our existing relationships, the ethics of how the work was done became a central focus. This was of course guided by ethical guidelines for research that have been developed over many years. For my part, I had to be very aware of the need to remain conscious and alert to the assumptions I make based on my position as a non-Indigenous person from a white, middle class, English speaking background. To use Addelson's (1994) words I had to be conscious of,

...the society that we act and enact every day, that we generate and regenerate through our acceptance and reinforcement of the authoritative 'norms' and 'standards. (p. 11)

Verran (2013), a non-Indigenous scholar who has a great deal of experience working in the area of generative research practices, suggests that knowledge work that seeks to decolonise needs to consciously employ 'interrupting tools'. This enables everyone involved to pay attention to and intentionally interrupt the research process to make space for difference and to enable the ability to work together in 'good faith' (Verran 2013).

A number of these 'interrupting tools' were developed as part of this research. Firstly, considerable time was devoted to exploring 'pre-methodological' questions, or 'the work before the work' (Palmer 2009). This focus on process required some unconventional choices within a PhD frame. Firstly, it required conscious attention to be paid to collaborative participation for the enitre length of the process associated with the $\mathrm{PhD}$ study. Secondly, ongoing reflection and evaluation was an element that needed to be built into the design from the very beginning. This resulted in an action refelction cycle around the question, 'How do we do research together in the intercultural space?' Arbon's (2008, p. 34) work around 'reciprocal relatedness' informed the choices made around how the work was done. As knowledge authorities in this field, the teacher participants became the co-creators of the process and co-contributors 
to the analysis work. Thirdly, at various times throughout the research the researcher and participants consciously and intentionally chose to talk and think together about what we were doing and how we were doing it. In Verran's (2013) language we were cultivating the 'collective disposition to interrogate the familiar' (p. 159). These 'interrupting tools' were used as mechanisms to ensure that everyone had a 'right' or 'good' feeling (Hall, 2016) throughout the processes and could come to the end of the process feeling that what had been achieve together was more than what could have been done alone. This is how Verran's term 'good faith' was interpreted in this instance. This meant that, in addition to the questions around supporting future generations of qualified teachers from remote communities, this doctoral research also offered a unique opportunity to inhabit, reflect on, evaluate and analyse ways of doing research that might offer decolonising strategies for future researchers.

\section{Literature Review - Relational Research That Generates 'Good Faith'}

The colonial legacy of research for Indigenous peoples is explored in great detail in Hall (2013). What is being explored here is how research processes can place relationships - between participants and between people and knowledge - as central to the work being done, with an emphasis on 'good faith'. Martin (2008) reminds us that when doing research with Indigenous people the research design must be co-constructed in order to remain open to the multiplicity of ways of knowing, being and doing. Wilson (2008, p. 11) suggests that the research itself must be considered 'ceremony'. Warlpiri scholar, Steve Patrick Pawu Kurlpurlurnu reminds us that for Indigenous epistemologies the knowledge lies in the relationships, not in the separate parts (Pawu Kurlpurlurnu, Holmes \& Box, 2008, p. 15). de Crespigny, Emden, Kowanko and Murray (2004) also concur with this notion of relationality, as does Chilisa (2011, pp. 108-122), reminding us that it is not just about relationships between researcher and community, but more importantly about understanding the relational ontologies and axiologies of Indigenous peoples. In this paradigm the researchers' relationship to knowledge itself is and must be different. According to Moreton-Robinson and Walter (2009, p. 6) Indigenous ways of knowing explicitly recognise that one cannot know everything, that everything cannot be known and that there are knowledges beyond human understanding. Additionally, they maintain that 'knowledge cannot be discovered or owned; it can only be revealed and shared. In research the Indigenous person is always the observer and Indigenous worldviews and perspectives are explicitly positioned as the lens through which the research seeks to reveal knowledge' (Moreton-Robinson \& Walter 2009, p. 12). As Chilisa (2011, p. 99) points out, this Indigenous perspective of research being about 'unveiling knowledge' may pose some challenges for an Academy that has previously be focused on the 'discovery' of 'new' knowledge.

This focus on the relationship between people and knowledge was not the only area where this research challenged academic 'norms'. The presence of pre-existing relationships, often seen as a risk or threat in the positivist view of research, is commonly seen as something advantageous to the quality of the research when working within and Indigenous/nonIndigenous collaborative space (Chilisa, 2011; Wilson, 2008). Verran (2013) advocates that research involving the collaboration of Indigenous and non-Indigenous people needs to have the intent of conducting itself in 'good faith' which means that at its core it needs to remain relational. Thrift (2004) talks about spaces of 'ethical encounter as being part of the real ethics of doing research. He suggests that things such as 'knowing when to wait for a response, knowing when and when not to foreclose a situation, knowing when to be playful and when to be serious...can open out the ethical possibilities of an encounter and allow both the researcher and the researched to trust their judgement' (Thrift, 2004, p. 120). He notes that these encounters expand our subjectivity, but do so in a frame of responsibility. This echoes Rose (2004) who talks about the need for an 'ethic of relational responsibility' as being central 
to the work of decolonisation. But Rose says that we must no longer see ethics as a 'closed system' but rather as a 'way of living....in vulnerability and openness to others' (Rose, 2004, $\mathrm{p}$ 8). She further explains that this needs to be an ethics of responsibility rather than guilt and it should focus on developing a human condition of 'living with and for others' (Rose, 2004 , p. 12). Finally, Rose suggests that ethics are revealed in our lives as they 'unfold within relationships of responsibility' (Rose, 2004, p.13). Moreton-Robinson \& Walter (2009, p. 6) underline the important principles of respect, reciprocity and obligation. This conception of relational ethics underpinning research processes corresponds strongly with ideas expressed by Indigenous scholars, and is widely considered to be a key aspect of decolonizing research practices.

\section{Method and Analysis: Co-constructing the Research Process and the use of 'Interrupting Tools'}

The group of teacher participants involved in this research were already known to me and I to them. There is accountability to each other through friendship, collegiality and a shared commitment to education. These relationships have seen the development of a rapport that enables honest and sometimes challenging conversations to take place in respectful and responsible ways. Ensuring a process of free and voluntary consent and participation in the project for the teacher participants was very important. In particular, as the principal researcher I did not want people to participate out of obligation to me or to our friendship. Ensuring the participants felt free to enter into but also opt out of the project was an important part of what needed to be negotiated in an ongoing way. Also important was the provision of many opportunities for the teacher participants to negotiate aspects of the project so that the spectrum of consensual participation was not simply about opting in or out, but ensuring that the research was done in ways that everyone felt happy with.

From the beginning, it was imperative that the sole focus was not just on the outcomes of the research but on the process itself, and how everyone was experiencing that process. To keep this focus there needed to be mechanisms for checking on our relational accountability to each other. This ongoing and intentional dialogue throughout the research process provided what Verran (2013) calls 'interrupting tools'. She talks about the need in decolonising knowledge work to pay attention to moments of 'epistemic disconcertment' and to be alert to the differences we encounter. These intentional conversations about the research process helped us to 'go deeper inside the encounter' (Verran, 2013, p. 147) to explore how the way we did things helped us to work in 'good faith' with each other. These mechanisms, or 'interrupting tools', outlined below, emerged and evolved as the research progressed.

\section{Conversational phase}

An extended 'conversational phase' was allowed for at the beginning of the research process. This enabled everyone to do as much talking as they needed to about the research questions, the implications of participation and the process of gathering the data in the form of teacher narratives. It also provided the teacher participants with time to have conversations with family and community members about the research and their role within it. This was important as it often enabled the participants to embed their understandings of the project in their first language by explaining it to and discussing it with other language speakers. The conversational phase enabled the researcher and the participants to conduct one main group discussion about the project where almost everyone was present. A number of ad hoc individual and group conversations also took place during this phase. Additionally, it was during the conversational phase that conversations occurred with leaders and Elders in the respective communities to 
explain the research we were doing and invite questions, conversation and input about the purpose and usefulness of what we were doing for people in that context. The conversational phase addressed a number of ethical principles for decolonising research practices, including showing respect for people and their communities, presenting yourself to people face to face, as well as looking and listening before speaking (Smith, 1999, p 120). It also allowed time for the development of agreements between two parties about the how the research would be conducted and disseminated and clarification of who was to benefit and how (Gorman \& Toombs, 2009, p. 11).

\section{Reflective conversations}

Upon the completion of the narrative recording for each participant, a final one to one reflective conversation was undertaken. The focus of this conversation was to document how both the researcher and the teacher participants were feeling about the research process thus far. It was intended as a moment of ethical and relational accountability to each other, to ensure that the consent given at the beginning of the process still felt true for both parties. These conversations were recorded in audio form and transcribed with the full consent of the teacher participants. These reflective conversations also gave practical action to a number of ethical principles for decolonizing research practices. Moreton-Robinson and Walter (2009, p. 6) underline the important principles of respect, reciprocity and obligation when undertaking research with Indigenous people. Smith (1999) and Gorman and Toombs (2009) both reinforce the importance of showing mutual respect. This practice also connected to notions of reciprocity spoken about by Arbon (2008) as well as tapping into ideas about 'ethical encounters' in research (Thrift, 2004) and an ethic of 'relational responsibility' talked about by Rose (2004).

\section{Shared analysis}

The analysis process used in the research was twofold. Firstly, transcripts from the recordings of our intentional reflective conversations, a total of seven documents, were uploaded into NVivo@ software. Ideas that repeated in the texts were identified by the researcher, often using the words or phrases from the conversations themselves. By the end of this process there were three areas that repeated themselves often enough to make them stand out. These three areas related to notions of time, the nature of existing relationships and ensured that multiple needs were met by the work being done. Conscious of Addelson's (1994) warning about the 'judging observer', and Verran's (2013) similar criticism of the instinct for an analyst to think she can step outside the situation, it felt important at this point to explore these three areas collectively. Waiting and allowing time before 'coming to concepts' (Verran, 2013) was an important part of this stage of the process. This collective exploration and analysis happened both through one-to-one conversations where and when possible, and then again when all of the participants came together at a two-day analysis seminar in Alice Springs. It was during this latter period of discussion that the words 'Anma', 'Marlpa' and 'Ngapartji' began to act as reference points between all of us to discuss these emerging insights.

\section{Findings and Discussion: Anma, Marpla and Ngapartji Ngapartji - Insights Into how we do Research Together in 'Good Faith'}

The findings discussed here were produced through the iterative conversations and analysis described in the previous section. While I acknowledge that I am the sole author of this paper and that carries with it an inherent hegemony, I have chosen to use the collective pronouns of 'we' and 'us' here to honour the collective process undertaken in developing these insights. Through paying attention to process, we were able to discover some important insights about 
what made a difference when we intentionally set about to work together in 'good faith'. These discoveries are discussed briefly below as examples of how to generate new, shared understandings when working together in a decolonising knowledge space.

Anma

... not usually, you know straight answer 'No' but you know, 'anma, give me time

The first area that we needed to pay attention to in how we worked together was in our differing notions of time. Together we ultimately came to talk about the importance of 'anma'. This is a Western Arrarnta word that has equivalences in other local Indigenous languages. For example, a similar concept in Warlpiri is expressed with the word 'murnma'. In Luritja and Pitjantjatjara the word often used is 'wanyu'. There are also related concepts in other Australian Indigenous languages further afield. 'anma' carries epistemologically complex understandings and can be interpreted in many ways including: waiting, giving space, waiting for the right time, not filling up all the space, being patient and waiting until the other person feels ready. While it might be perceived as a passive term where nothing is happening, it is often quite an active space of preparation and foreshadowing.

We discovered that 'anma', or waiting, was an important part of our collaborative work. This waiting was a space that allowed time for many things to occur. It allowed time for good communication to happen and allowed everyone to feel ready and prepared. This was really important for meeting the requirements of the Western academic research consent process, but doing so in a way that was not pushy, rushed or false. Waiting for the 'right time' and until people indicated their readiness felt more informed, more like genuine consent and ensured that the data, in the form of the teacher narratives, that came from that process emerged comfortably and confidently. This perhaps indicates a point of difference in relation to ethics, which can be identified and granted into the future through a western metaphysics, but in Indigenous knowledge systems and understandings it is always provisional as reality itself emerges. Approaching things with 'anma' created a space for patience, consideration and a giving over of control when required. This enabled participants to have agency and control over their choice to participate far beyond the binary options of opting in or opting out of the research.. Participants continued to engage in the process until they felt the time was right, or their lives allowed enough time for recording the narratives. The teacher participants also felt a sense of control over their participation in the process. Working with a philosophy of 'anma' ensured a space that allowed for a respectful way of entering into work with people and provided enough time for everyone who needed to be involved in the process to be included. Often in research, the perception is that the principal researcher needs to be in control of the process. There were many times when I needed to give up control and trust in my research collaborators. Sometimes this was about letting someone else plan how and when we would spend our time together and being flexible when plans changed. Building a collective understanding of 'anma' gave us a way of thinking about time not as sequential and linear, but as patterned, seasonal and emerging. The research process became not so much something that we planned for, but rather something that we paid attention to and allowed to unfold. This allowed us to meet the work with readiness when the time was right. 
Marlpa

...we can't leave you by yourself, we gotta use everyone's eyes and ears and search for it

The second area that we needed to pay attention to in how we worked together concerned the nature and role of our existing relationships. Together we ultimately came to talk about the role of 'marlpa'. This is a word that is used by Warlpiri, Luritja and Pitjantjara language speakers. It has equivalences in many other Indigenous languages, for example in Western Arrarnta the concept is often expressed using the word 'ilkwatharra'. It is often translated simply as 'company' but the epistemological understandings of this word go much deeper. At its core 'marlpa' is relational. It is about friendship, doing things together and not leaving anyone out. It is a way of being with others that ensures harmony, connectedness and relational responsibility. 'Marlpa' is often experienced bodily, as a 'good feeling'. It was of central importance to how we worked together in this research process.

There were pre-existing relationships between the teacher participants and myself, as well as longer-term relationships between the teacher participants themselves. This enabled us to operate from a position of relational trust, shared experience and commitment, and accountability to each other. Knowing each other for so long and with such familiarity enabled flexibility, gave us the ability to read the subtler nuances of communication and strengthened our commitment to working towards a common purpose. New work required additional negotiation, but it meant that we were starting from a place of knowledge and trust that does not exist if the researcher and participants are unknown to each other. A large part of the commitment of these teachers to work on this research was not necessarily about their relationship to me, but their relationship to each other. The teacher participants have a sense of community born out of their shared journey working in schools and undertaking their teacher education together. They provide 'marlpa' for each other that cannot be provided by other people, including me. Relationships and 'marlpa' provided an important accountability mechanism into the research process. This is important when considering the traditionally privileged and powerful role of the principal researcher. I was able to trust that if I was headed in the wrong direction, the strength of our relationships meant that people would find honest ways to tell me and show me that. The feeling of 'marlpa' was also an important reminder that it wasn't all about the research. Sometimes 'marlpa' was about making time and space to be together doing other things: storytelling, hunting, teaching or laughing. Mostly it was just about being together. These shared activities were also ways of entering into the research process more gently and comfortably; of starting from a point of 'marlpa' and re-establishing that trust relationship before the recording devices got turned on. It was important preparation work that needed to be done each time we came together.

\section{Ngapartji Ngapartji}

...my history is helping both you and me because that's like our country helps us to do our language and culture

The third area where we experienced both disconcertment and 'good faith' as we worked together was in our ability to ensure that multiple needs were met by the work we were doing. Together we talked about this using the phrase 'ngapartji ngarpartji' which can be translated in many ways. In discussion we decided that the best translation to English to use was 'you give something to me and I give something to you'. Warlpiri speakers will sometimes borrow this phrase from Luritja, but will also use the word 'watinyarra' meaning 'equal' or 'level' to express 
something similar. In Western Arrarnta it is often expressed as 'kapanha'. To encapsulate this concept in English we might talk about reciprocity or mutual generosity. In practice this concept was enacted in many different ways.

Through this process of exploration we came to acknowledge what mutual generosity actually looks like in an intercultural space. Helping each other out is about everyone getting their needs met with the collective resources that we possess. Finding ways to do this that are balanced and respectful of all can be challenging. At times doing so meant the difference between research sessions going ahead or not. Learning from each other was a defining feature of the reciprocity that existed throughout my time of knowing and working with these teachers and was a central tenet of what we did in this research work.

Reciprocity emerged through the sharing of ideas happened in everyday conversations about things that mattered to us, while driving somewhere or sitting together of an evening. Then there were other times when I was the one who was doing most of the learning through conversations with Elders, time spent on country and visits to significant places. It was through moments of 'ngapartji ngarpartji' that I began to understand the research itself as being an embedded in the lives of participants, my own life, and in interconnected ways to the life of all those we came into contact with. The stories being told were indivisible from all knowledge for the tellers, and I needed to begin to understand this about the stories we were recording together. This was challenging for me as it seemed to increase my sense of obligation and responsibility to do it 'right', whatever that meant. Perhaps this points towards an ongoing epistemological disconcertment that needs to be dwelt in longer?

Finally, the participants and I frequently discussed the 'good feeling' that we often had throughout the process. In some ways this is a type of reciprocity that lies in the well-being that the teacher participants got in return for offering their stories as the data for the research. At other times it was the 'good feeling' of working together on a shared problem that we all cared deeply about. Steven Patrick Pawu-Kurlpurlurnu, a Warlpiri scholar from Lajamanu community, talks about this in his writings on Ngurra-Kurlu. He uses the following phrase to describe this 'good feeling', 'People tasted it, they liked that taste in their mouth and they came back for more' (Pawu-Kurlpurlurnu, Holmes \& Box, 2008, pp. 7-8). This is similar to what Verran (2013) is referring to when she talks about doing things together in 'good faith' from which something different and interesting emerges.

\section{Conclusions}

The research process used in this study was not without fault. It was still confined and constricted by the trappings that come along with the PhD frame, and because of that was vulnerable to the neo-colonial reality of the western academic system. There were time constraints, language constraints and ethical constraints, to name but a few. All of these were limited by my capacity as a non-Indigenous principal researcher and by the administrative constraints of the $\mathrm{PhD}$ process itself. Even the process of writing this paper, and me being the only author, runs the risk of the teacher participants being 'written about' and some may perceive this as their voices being 'written out'. But hopefully the benefits of acting together in a decolonising way throughout the research, outweigh those risks. Perhaps by naming some of these inherent problems, the hope is that this will become part of an iterative process that informs other types of responsive research in the future.

Out of a desire to do research in a decolonising way, choices were made about how to interrupt the ubiquitous and powerful 'norms' of the research process. The focus was not solely on the outcomes of the research, but intentional space was made to notice how the work was done 
together. In particular, time was taken to think and talk extensively about the work to be done together. Finding the 'right time' to do the work was prioritised and emphasised. 'Anma' provided an insight into how decolonising work can be done. The deep trusted relationships built over time acted as a compass to help navigate the right way to do the research together. 'Marlpa' was a force that shaped the decolonising research space. The immense knowledge, capabilities and experience that everyone brought to the process was valued. A spirit of reciprocity and generosity was honoured. Rather than the research process being a one-way street that only benefits the researcher, 'ngapartji ngarpartji' became a foundation through which the multiple needs of all participants could be met. Through the 'interrupting tool' of conversation both the teacher participants and I were able to identify that we have all been left with a 'good feeling' about what we have done together.

There is an inherent danger in labelling and categorising this learning. Anma, Marlpa and Ngaparji Ngarpartji are words that point towards something deeper, with multiple meanings and, in some ways, something that is unable to be known by those who were not inside the experience. They are used here not to establish them as a prescription for others. Instead they are offered as a kind of narrative that tells the story of the process. They were ways of doing and being that helped develop better understandings of our differences in how we approached things. This in turn helped us to find ways of doing the research that left everybody with a 'good feeling'. It is this relational, participatory approach, where the responsibility of participation and reflecting on our participation is collectively shared, which feels most important. It is the process and the approach that has that ability to decolonise our knowledge work. By intentionally setting up some 'interrupting tools' and by creating the time and space to talk together about how things needed to be done important insights about 'good faith' were gained. These insights into process have the capacity to lead to new decolonising knowledge spaces. 


\section{References}

Addelson, K. P. (1994). Moral passages: toward a collectivist moral theory. New York: Routledge.

Arbon, V. (2008). Arlathirnda Ngurkarnda Ityirnda - Being-Knowing-Doing, De Colonizing Indigenous Tertiary Education. Tennerife, QLD.: Post Pressed.

Chilisa, B. (2011). Indigenous research methodologies. Thousand Oaks, CA.: Sage Publications.

de Crespigny, C., Emden, C., Kowanko, N, \& Murray, H. (2004). A 'partnership model' for ethical Indigenous research. Collegian, 11(4), 7-13.

Gorman, D. \& Toombs, M. (2009). Matching research methodology with Australian Indigenous culture. Aboriginal and Islander Health Worker Journal, 33(3), 4-7.

Hall, L. (2014). 'With' not 'about' - emerging paradigms for research in a cross-cultural space. International Journal of Research \& Method in Education, 37(4), 376-389.

Hall, L. (2016). Moving Deeper into Difference - Developing meaningful and effective pathways into teacher education for Indigenous adults from remote communities (PhD). Darwin: Charles Darwin University.

Institute for Aboriginal Development (2002). Central Australian Aboriginal languages: current distribution (map). Alice Springs: IAD Press.

Martin, K. L. (2008). Please knock before you enter: Aboriginal regulation of outsiders and the implications for researchers. Teneriffe, Qld.: Post Pressed.

Moreton-Robinson, A. \& Walter. M. (2009). Indigenous methodologies in social research. Social Research Methods, (2), 1-18.

Palmer, P. (2009). A Hidden Wholeness: The Journey Toward an Undivided Life. San Francisco: Jossey Bass.

Pawu-Kurlpurlurnu, W. J., Holmes, M. and Box, A. (2008). Ngurra-kurlu: A way of working with Warlpiri people. Alice Springs: Desert Knowledge CRC.

Rose, D. B. (2004). Reports from a wild country: ethics for decolonisation. Sydney: University of New South Wales Press.

Smith, L. T. (1999). Decolonizing methodologies: Research and Indigenous peoples. London: Zed Books.

Thrift, N. (2004). Practising Ethics. In M. Pryke, G. Rose \& S. Whatmore, Using Social Theory: thinking through research (pp. 105-120), London: Sage.

Verran, H. (2013). Engagements between disparate knowledge traditions: Toward doing difference generatively and in good faith. In L. Green (Ed.), Contested Ecologies: dialogues in the south on nature and knowledge (pp. 141-161). Cape Town, South Africa: Human Sciences Research Council Press.

Wearne SM. Pilot study on the factors that influence learning by general practice registrars in central Australia. Rural and Remote Health (Internet) 2003; 3: 223. http://www.rrh.org.au/articles/ subviewnew.asp?ArticlelD=223 (Accessed 3 October 2016)

Wilson, S. (2008). Research is ceremony: Indigenous research methods. Black Point: Fernwood Publications. 